\title{
Detection of Bearing Damage Using Stator Current, and Voltage to Cancel Electrical Noise
}

\author{
Ali Ibrahim, ${ }^{1,2,3}$ Frédéric Bonnardot, ${ }^{1,2,3}$ Mohamed El Badaoui, ${ }^{1,2,3}$ and François Guillet ${ }^{1,2,3}$ \\ ${ }^{1}$ Université de Lyon, F-42023, Saint Etienne, France \\ ${ }^{2}$ Université de Saint Etienne, Jean Monnet, F-42000, Saint-Etienne, France \\ ${ }^{3}$ LASPI, F-42334, IUT de Roanne, France
}

Correspondence should be addressed to Frédéric Bonnardot, frederic.bonnardot@univ-st-etienne.fr

Received 27 July 2010; Revised 15 January 2011; Accepted 28 January 2011

Academic Editor: Antonio Napolitano

Copyright (C) 2011 Ali Ibrahim et al. This is an open access article distributed under the Creative Commons Attribution License, which permits unrestricted use, distribution, and reproduction in any medium, provided the original work is properly cited.

\begin{abstract}
This paper investigates the detection of a bearing defect in an asynchronous machine by analysing the electric signals. For this purpose, it is considered that the voltage is imposed and independent of mechanical aspect and that the mechanical defect appears only in the current thanks to the variation of impedance. Wiener filtering is used to extract mechanical information contained in the electrical current; this will then enable the use of statistical indicators such as kurtosis which identify the presence of a defect. Initially, the small fluctuation in electric current around the electric cycle $(50 \mathrm{~Hz})$ is reduced in order to reinforce cyclostationarity. Then, a filter between the voltage and current is estimated, using Wiener's technique. Since the voltage is decorrelated of mechanical elements, the residual signal (current - predicted current) contains the mechanical part. This study is corroborated by an envelope analysis of the vibration signal. Experimentation on a faulty outer raceway bearing has shown the excellent performance of the proposed method. This method is easier to implement since the sensors' position does not influence the measure the way it does when using accelerometer sensors. This diagnosis could be embedded into a fed converter. However, it is less sensitive than a direct measure of the defect (accelerometer).
\end{abstract}

\section{Introduction}

Asynchronous machines are used a lot in industry because of their advantages over other electric machines: standardisation, robustness, and low purchase and maintenance cost. It is widely used in the metallurgical and chemical industries, in energy production, and in the propulsion of vehicles and ships.

Asynchronous machine failures are due to stator, rotor, and bearing faults. More than $40 \%$ of all motor failures are bearing related [1-3]. Sometimes, bearing faults might manifest themselves as rotor asymmetry faults [4] (usually listed under the category of eccentricity-related faults). The breakdown of one part of a machine can stop the complete process and cause losses in terms of time and money. Therefore, it led to the implementation of monitoring systems [5-8], so as to be able, at any time, to provide information on the operating condition of the various parts of the production process, such as asynchronous machines and their load. In most situations, diagnosis is based on the analysis of mechanical signals (acceleration, speeds, etc.) which have proven their effectiveness [9-11].

However, the use of mechanical signals cannot always be used (underwater pumps, hostile environment, etc.). In such conditions, it is better to move the data acquisition to a more suitable environment. In this paper, we suggest to use the motor's current and voltage as they are available anywhere via the electric cables. This type of measurement (current and/or voltage) is a noninvasive method to extract the information needed to provide system diagnosis and thus ensure an effective monitoring [12-16].

Stator current monitoring has been widely developed in order to diagnose bearing faults, but the major problem with the previous method is that the mechanical defects are often drowned in noise. It does not allow a good diagnosis based on the electric current. In this paper, the nonsynchronism (i.e., different cyclic frequencies) between the electrical and mechanical phenomena is used to dissociate mechanical information. It also enables us to improve the detection of mechanical defects while the fault is still at an early stage. 


\section{Cyclostationarity}

2.1. Origin of Cyclostationarity. Rotating machines produce cyclic signals. Three kinds of cycles can be found in electric current: electrical cycles (50 Hz and harmonics), mechanical cycles, and their combination (modulation). With slight speed fluctuation, cycles linked to mechanical phenomena are periodic versus the mechanical angle, and cycles linked to electrical events are periodic with the electrical "angle" (phase).

Unfortunately, the angle is not strictly proportional to time due to speed or electrical power fluctuations. In order to take advantage of the electrical cycle, the signal is synchronised with the electrical period, making the statistics associated with electrical events become periodic (cyclostationary signal [17]).

This periodicity may be an important characteristic that should be reflected in an appropriate probabilistic model. Stationary processes, with their time-invariant probabilistic parameters, are in general inadequate for the study of such phenomena. Nonstationary models take care of parameters variations, but, do not take advantage of their periodic nature. Between these two models, cyclostationarity deals with periodically varying random processes and enables us to take advantage of the electric cycle.

Cyclostationarity results from a coupling between a periodic phenomenon and another stationary, but random, phenomenon. There is an example:

$$
x(t)=A(t) \sin \left(2 \pi f_{0} t\right),
$$

where $A(t)$ is random, stationary, and zero average (white noise).

This signal $x(t)$ cannot be characterised by a traditional Fourier analysis because it is not stationary. But a spectral correlation with a zero delay makes it possible to detect its cyclic frequency.

2.2. Definition of Cyclostationarity. Let $T$ be a cyclic period, $\alpha=k / T, k$ th is cyclic frequency harmonic $(k=0,1,2, \ldots)$, and $\tau$ the time delay.

A process, $x(t)$, is said to be cyclostationary at order 1 if its mean value $m_{X}(t)$ is periodic with the same period $T$ [17]:

$$
\begin{aligned}
m_{X}(t) & =E[x(t)]=E[x(t+T)]=m_{X}(t+T) \\
& =\sum_{\alpha} M_{X}^{\alpha} \cdot \exp (2 j \pi \alpha t),
\end{aligned}
$$

where $M_{X}^{\alpha}$ are the Fourier coefficients

$$
M_{X}^{\alpha} \triangleq \lim _{T \rightarrow \infty} \frac{1}{T} \int_{-T / 2}^{T / 2} m_{X}(t) \cdot \exp (-2 j \pi \alpha t) d t .
$$

The typical example of order-1 cyclostationarity is a gearbox signal which contains a periodic part associated with gears and a random part associated with noise and other mechanical elements. Another example could be a sine wave at $50 \mathrm{~Hz}$ with an additive noise.
A process, $x(t)$, is said to be cyclostationary at order 2 if its autocorrelation $R_{X}(t, \tau)$ is periodic with the same period T:

$$
\begin{aligned}
R_{X}(t, \tau) & =E\left[x(t) x^{*}(t-\tau)\right]=R_{X}(t+T, \tau+T) \\
& =\sum_{\alpha} R_{X}^{\alpha}(\tau) \cdot \exp (2 j \pi \alpha t),
\end{aligned}
$$

where the Fourier coefficients $R_{X}^{\alpha}(\tau)$ are known as the cyclic autocorrelation functions:

$$
R_{X}^{\alpha}(\tau) \triangleq \lim _{T \rightarrow \infty} \frac{1}{T} \int_{-T / 2}^{T / 2} R_{X}(t, \tau) \cdot \exp (-2 j \pi \alpha t) d t .
$$

For $\tau=0$, the autocorrelation is the signal energy. Therefore, a cyclostationary signal at order 2 has a periodic power.

If no cyclic frequencies are present in the signal, $R_{X}^{\alpha}(\tau)=$ 0 for $k \neq 0$, then we have a stationary process.

In practice, only one realisation is available. Therefore, the set average is replaced by cycle average. The estimations of cyclic averages $m_{X}(t)$ and cyclic autocorrelations $R_{X}(t, \tau)$ are given by

$$
\begin{gathered}
m_{X}(t)=\frac{1}{k} \sum_{n=0}^{k-1} x(t+n T), \\
R_{X}(t, \tau)=\frac{1}{k} \sum_{n=0}^{k-1} x(t+n T) x^{*}(t+n T-\tau) .
\end{gathered}
$$

The cyclic power spectrum (CPS), at a given cyclic frequency $\alpha_{i}$, is defined by the Fourier transform of the cyclic autocorrelation function, $S_{X}^{\alpha_{i}}(f)=\operatorname{TF}\left\{R_{X}^{\alpha_{i}}(\tau)\right\}$. The CPS measures for a given cyclic frequency, $\alpha_{i}$, the interaction between two shifted spectra of $x(t): X(f-(\alpha / 2))$ and $X(f+(\alpha / 2))$. If these two quantities are linked (side bands spaced at a rolling element characteristic frequency $\left.f_{\text {roll }}\right)$, the result is nonzero for each $\alpha_{i}=k \cdot f_{\text {roll }}$ ( $k$ is an integer).

\subsection{Example of Cyclostationarity}

2.3.1. Impacts with Random Amplitude. Let $x(t)$ be a series of periodic impacts with a random amplitude (average amplitude of 1 with a standard deviation of 0.1 ). Let the sign of the impact also be random.

Figure 1 presents the signal and a cyclostationary analysis. Figure 1(b) shows the superposition of each impact and reveals the periodic nature of the process. Nevertheless, since the impact sign is random, the synchronous average displayed in Figure 1(c) is zero. The process cycle can only be revealed by studying its power (i.e., cyclostationarity at order 2 ). Figure $1(\mathrm{~d})$ shows $R_{X}(t, 0)$ which is simply the synchronous average of the squared signal. The autocorrelation at lag $\tau=0$ reveals the periodicity of the process.

2.3.2. Impact with a Random Phase. Let us consider the response impacts of period $T=0.1 \mathrm{~s}$ with a random phase $\varphi_{i}$ :

$$
x(t)=\sum_{i} e^{-\alpha(t-i \cdot T)} \cdot \sin \left[2 \pi f(t-i \cdot T)+\varphi_{i}\right]+n(t),
$$




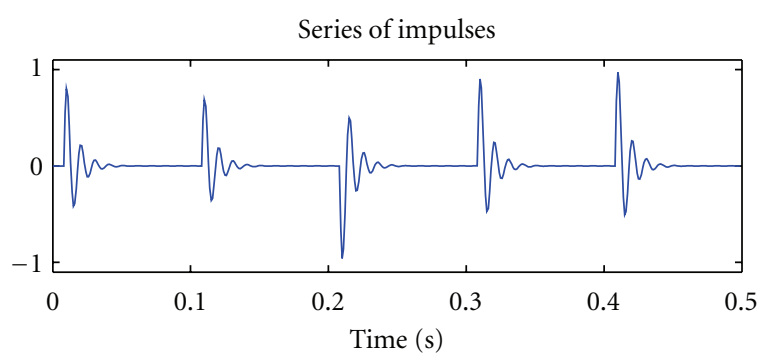

(a)

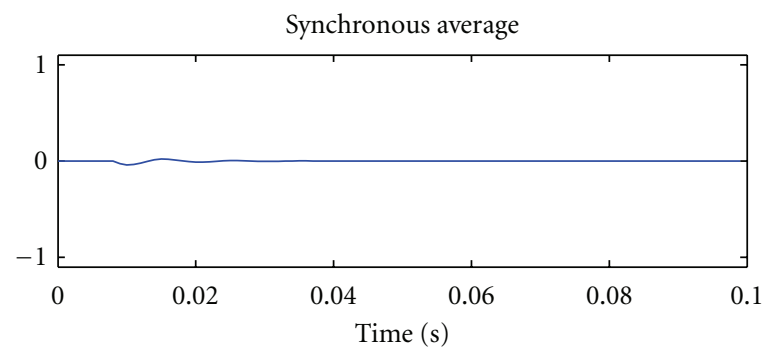

(c)

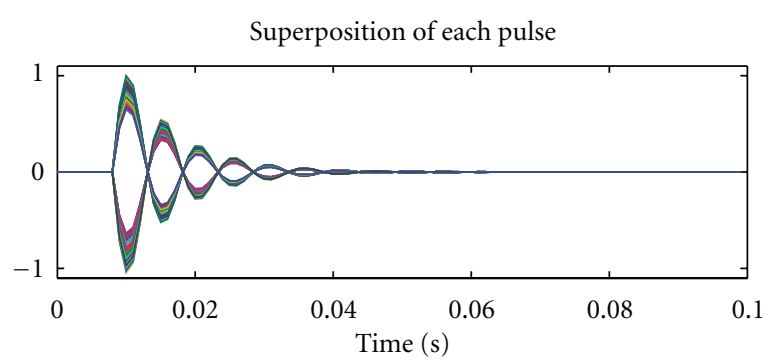

(b)

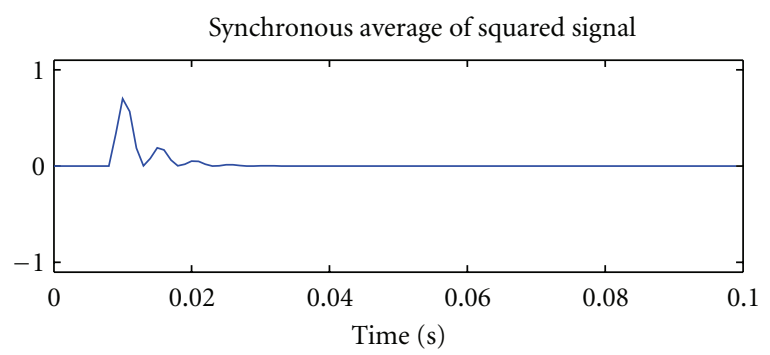

(d)

Figure 1: Analysis of a series of impulses.

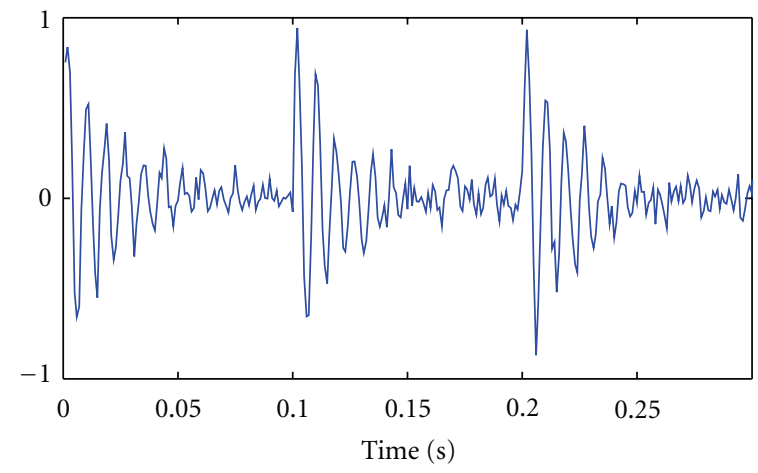

(a) signal

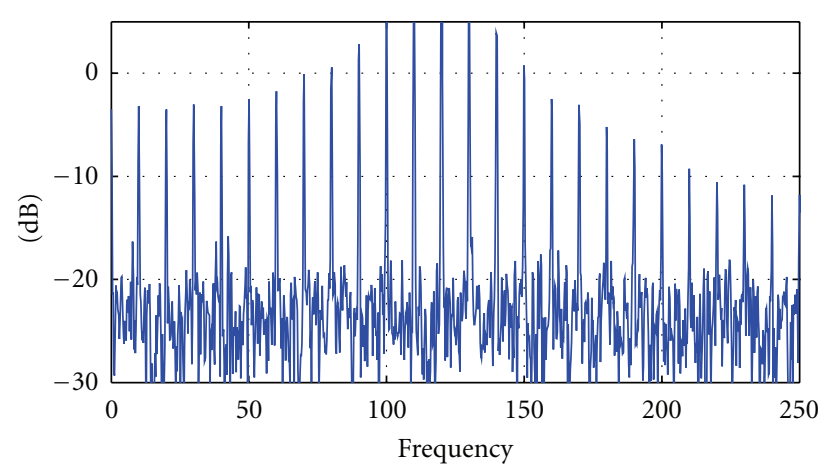

(b) signal spectrum

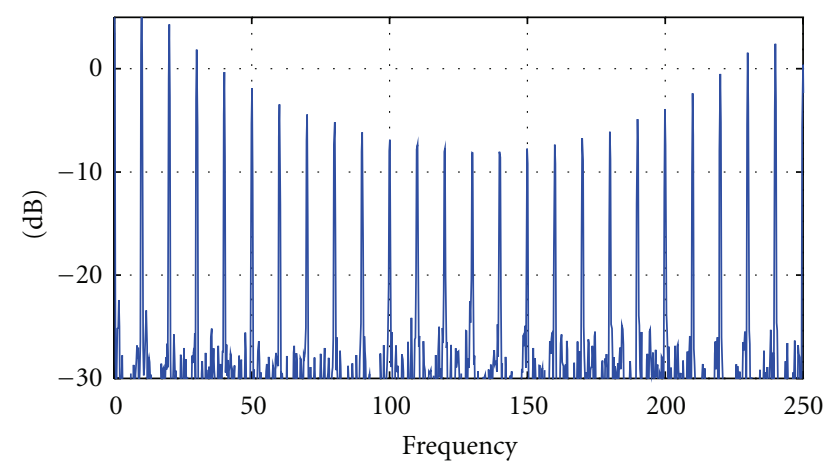

(c) Squared signal spectrum (peaks spaced of $10 \mathrm{~Hz}$ )

FIgURE 2: Impacts with no phase variation for sine waves.

where the damping $\alpha=50, f=120 \mathrm{~Hz}, i$ corresponds to the impact number, $\varphi_{i}$ is the random phase associated with the $i$ th impact, and $n(t)$ is a random Gaussian noise.

Figure 2 shows the signal with $\varphi_{i}=0$. In this case, the signal period of $10 \mathrm{~Hz}$ can be seen on the signal spectrum
Figure 2(b). Figure 2(c) shows the spectrum of a squared signal (i.e., spectrum of the power). The cyclic frequency $10 \mathrm{~Hz}$ also appears in this spectrum.

Figure 3 shows a signal in the case of a random phase $\varphi_{i}$ (uniform law between 0 and $2 \pi$ radians). The classical 


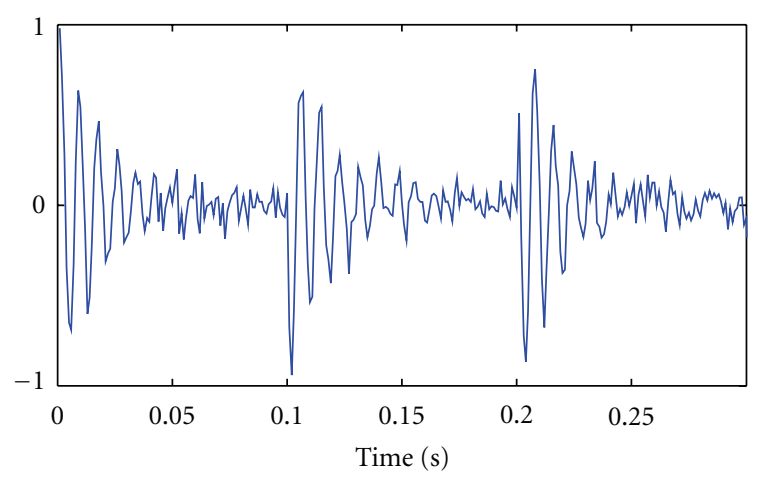

(a) signal

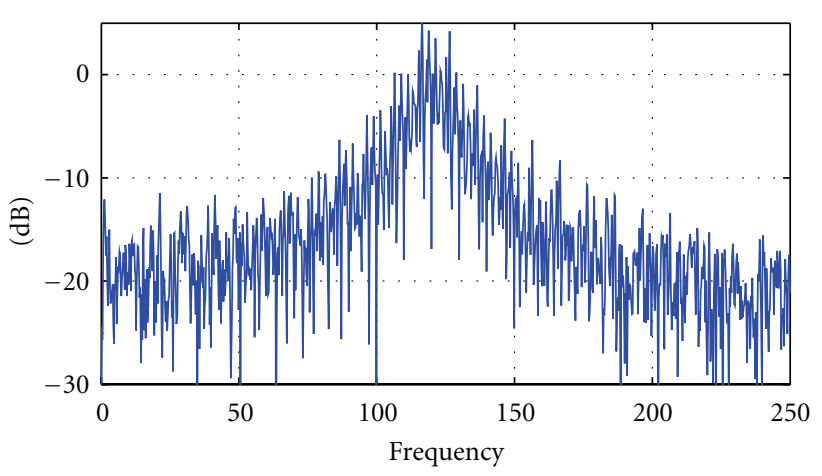

(b) signal spectrum

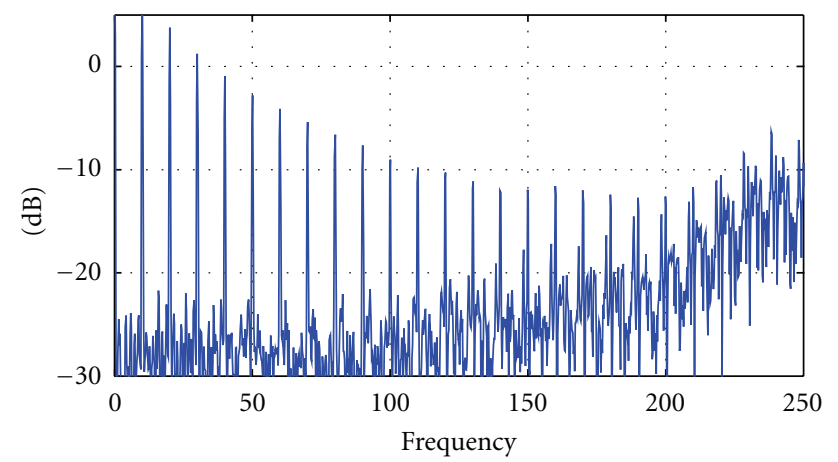

(c) Squared signal spectrum (peaks spaced of $10 \mathrm{~Hz}$ )

FIGURE 3: Impacts with random initial phase for sine waves.

spectrum (Figure 3(b)) does not reveal the signal period because of the random phase. Therefore, the cycle is only visible when working with the squared signal (in order to study cyclostationarity of order-2). It is important to notice that a shift of $2 \pi$ radians in the sine wave only represents a shift of $1 / 12$ of the signal cycle $T$.

2.3.3. Bearings. A typical example of cyclostationarity at order-2 process is faulty rolling elements of the bearing. The position of the faulty ball impacts slightly fluctuates against time. Figure 4 shows a bearing signal split into slices of 1 cycle. Each slice could be considered as a realisation. The cyclostationary at order- 1 term is reduced even though a periodic power distributed around the impact position remains cyclostationary at order 2 .

\subsection{Application of Cyclostationarity to Bearing Diagnosis. In} [18], it has been proved that a close relationship exists between the cyclic power spectrum and the squared envelope spectrum. Equation (8) illustrates this relation:

$$
\int_{f_{1}}^{f_{2}} S_{X}^{\alpha_{i}}(f) d f=\lim _{T \rightarrow \infty} \frac{1}{T} \int_{-(T / 2)}^{T / 2}|\widehat{x}(t)|^{2} \exp \left(-j 2 \pi \alpha_{i} t\right) d t
$$

where: $\hat{x}(\mathrm{t})$ is the filtered version of signal $x(t)$, obtained by band-pass filtering in the frequency band $\left[f_{1} ; f_{2}\right]$ around

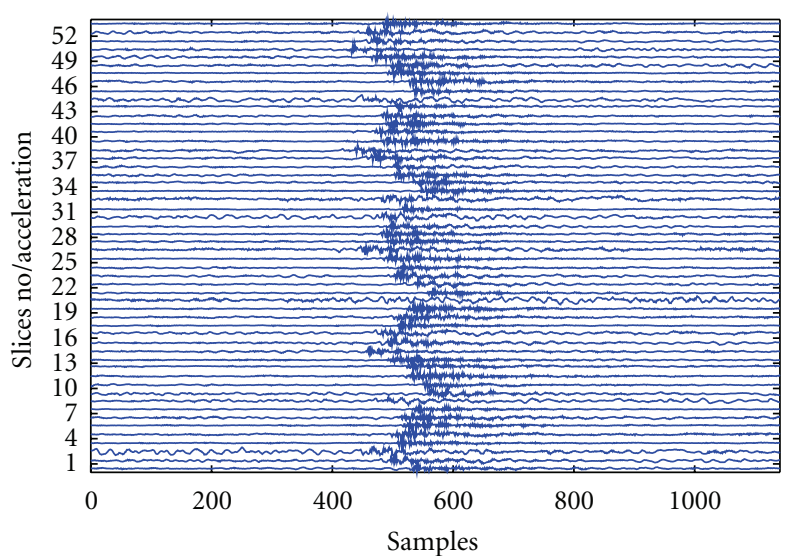

FIGURE 4: Slices of bearing signal.

a high-frequency resonance (where the signal-to-noise ratio is maximised). As stated in [19], this relationship is valid provided that $\alpha_{i} \ll f_{2}-f_{1}$. This condition is always met when dealing with bearings in rolling element.

This relationship simply means that the envelope Fourier transform frequency gives a cumulative cyclic power versus the cyclic frequency (i.e., indicates what the signal cycles and their "power" are). The Fourier transform envelope is easier to compute, however, the information about the two 
frequencies $f_{1}$ and $f_{2}$, which interact in order to produce a cycle $\alpha$, is lost.

Envelope analysis is a widely used technique to identify periodic impacts from a vibration signal even if those impacts have very low energy level or even if they are hidden by other vibration signals (the high bandwidth of bearing signal makes it possible to work in a frequency not excited by any other mechanical parts). Bearing failures are one of the most common industrial machines faults, and the envelope analysis is primarily used to detect and diagnose the defects of bearing's rolling elements. When a damage develops, the vibration becomes amplitude modulated due to periodic changes in the forces. The low-frequency vibrations, including the fault symptoms of the bearing rolling element, are filtered away in order to extract only the modulated periodic information from the more sensitive and pure envelope signal [20].

Processing Algorithm. The study of the envelope makes it possible to analyse the shape of the signal, in particular, when the required defect excites a mode of resonance of the structure. It consists of filtering the signal around a frequency of identifiable resonance in the spectrum and seeking the modulation caused by the repetition of the forces generated by the required defect. The determination of modulation frequencies (shock repetition rates, associated with the knowledge of the kinematics of the installation) makes it possible to locate the origin of a defect early and quickly, even when the effect of the defect is drowned in background noise. This technique is widely used in the diagnosis of defects with shock characteristics, even at low speed, since the defects are not found in the low frequency band, but around carrier frequencies, which are usually in the high-frequency domain. [21].

The numerical steps of envelope detection are as follows

(1) Apply Fourier transform to the temporal signal.

(2) The spectrum thus defined makes it possible to isolate resonances from the system.

(3) The temporal signal is band-pass filtered in order to obtain a reduced spectrum around the main frequency of the system.

(4) Then analytic signal is extracted (see the appendix).

(5) The temporal envelope signal is then obtained by inverse Fourier transform and taking the modulus.

This signal is seldom employed as a tool for analysis. The spectrum of the envelope or squared envelope are generally used.

Envelope analysis filters away the low rotational frequencies of the complex signal. The repetitive components at high frequencies are amplified and converted into spectrum while the noise of the machine is reduced with a significant signalto-noise ratio. If vibrations appear in the spectrum envelope which are related to the frequencies of a bearing defect, one can deduce that a defect is developing.

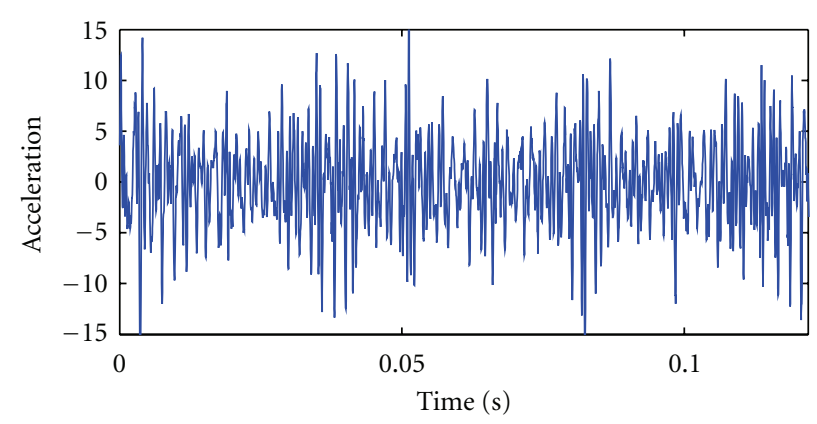

Figure 5: Acceleration measured during 5-shaft revolutions.

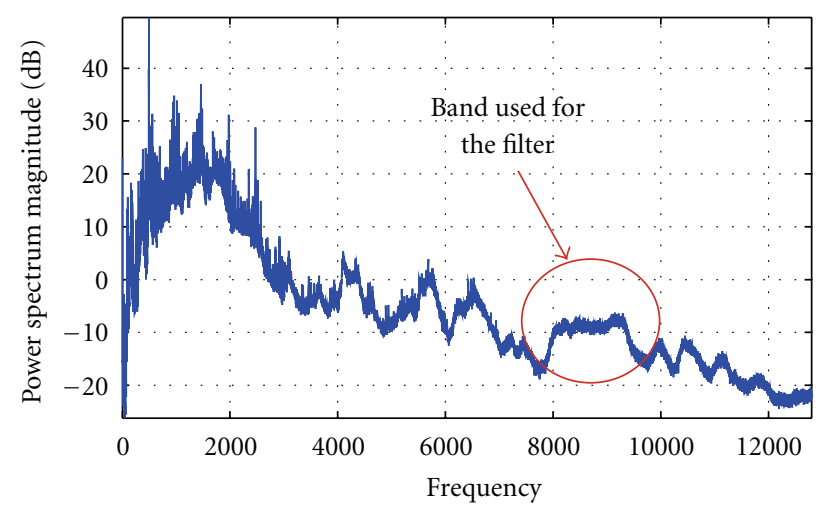

Figure 6: Power spectrum density of vibratory signal.

Envelope analysis purifies the vibratory signal. The total temporal signal is difficult to interpret, the components with low energy being drowned among the components of high energy and the noise. The temporal envelope signal can show the impulses caused by a defect on the external race of a bearing.

Figure 5 shows the acceleration produced by a bearing during 5 shaft revolutions. The bearing defect does not clearly appear. In order to do an envelope analysis, the spectrum is computed in Figure 6 (enlargement in Figure 7). A resonance located between $8 \mathrm{kHz}$ and $10 \mathrm{kHz}$ is extracted by band-pass filtering. At such high frequency, the gearbox contribution becomes low. The envelope spectrum is afterwards computed in Figure 8.

The cyclic power spectrum of a vibratory signal is presented in Figure 9. We can note some frequency lines at $k \times 63 \mathrm{~Hz}(k=0,1,2, \ldots)$ due to bearing fault.

The power spectrum density of the squared envelope (Figure 8) corresponds to a bearing turning at $24.7 \mathrm{~Hz}$ where the defect is localised on the external race. The first peak at $63 \mathrm{~Hz}$ corresponds to the BPFO frequency and the other peaks are the harmonics. A peak at $24.71 \mathrm{~Hz}$ associated with the bearing rotation frequency is also present.

Envelope analysis is very effective on the vibratory signals but it does not function on the electric signals because they are not cyclostationary at order 2. The present application is interesting within the framework of the diagnosis of induction machines based only on electrical measurements, hence the interest in finding a filter which will enable the 


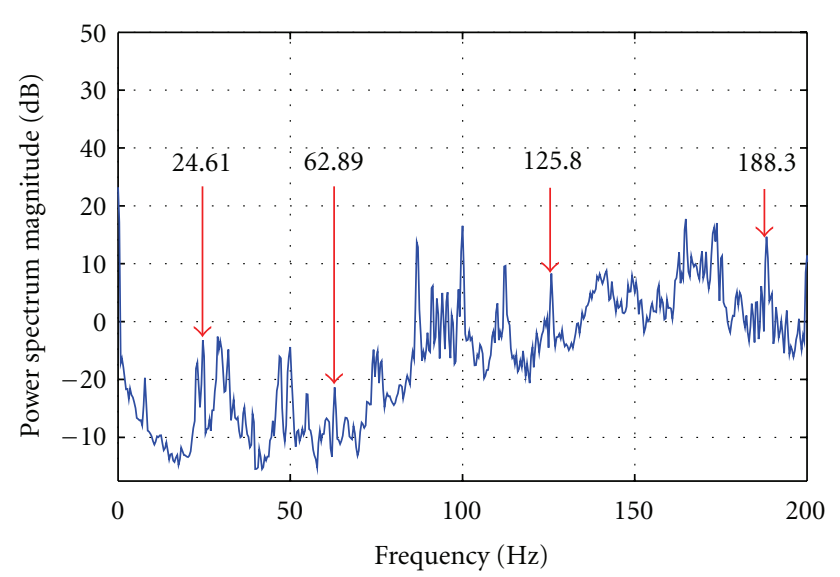

Figure 7: Power spectrum density of vibratory signal (low frequencies).

extraction of the maximum amount of information about mechanical phenomena from the electrical current.

\subsection{Enhancement of Cyclostationarity in Our Application.} The power supply frequency fluctuates around $50 \mathrm{~Hz}$; this fact influences the cyclic characteristics (cyclostationarity) of the electric signals. This fluctuation produces a nondeterministic cyclic period which dispels the energy around the mean cycle. For this, we propose to resynchronise these signals depending on their cyclic frequency. Therefore, the cyclic period becomes constant and the energy is concentrated on the cyclic frequencies. The cyclostationarity retains linear relation between signals, which is really significant for the correct operation of the Wiener filter.

The process of synchronization is as follows. Firstly, we cut each signal in slices corresponding to the cycles, an integer number of points per cycle, that is, 512 points if the sampling frequency is $25.6 \mathrm{kHz}$. The result, which consists of a superposition of sine wave slices, is displayed in Figure 10(a). Since it is not easy to visually distinguish the sine waves, a " $*$ " indicates the position of the maximum for each slice. This marker enables us to easily locate the start of each period. During the observation time, the main period is slightly higher than $20 \mathrm{~ms}$, therefore, the position of the maximum is shifted right. Since this period variation is random, the shift is also random: markers cannot be linked with a line.

By analysing precisely the fluctuation (i.e., studying the distance between two maximum locations), it appears that the maximum shift between two consecutive periods represent $+/-0.6 \%$ of $0.2 \mathrm{~ms}$.

Secondly, we calculate the delay between the first cycle, taken as a reference, and the other cycles. The shift is simply calculated by using the maxima of two sinusoids positions. After synchronisation, the signal is rebuilt by assembling synchronized slices. There are other ways to estimate the delay between the sections, such as correlation and zero passage. The current is synchronised in the same manner as the voltage [15]. Figure 10 represents various cycles of the current; these cycles are acquired during 40 seconds, approximately, to highlight the fluctuations of the

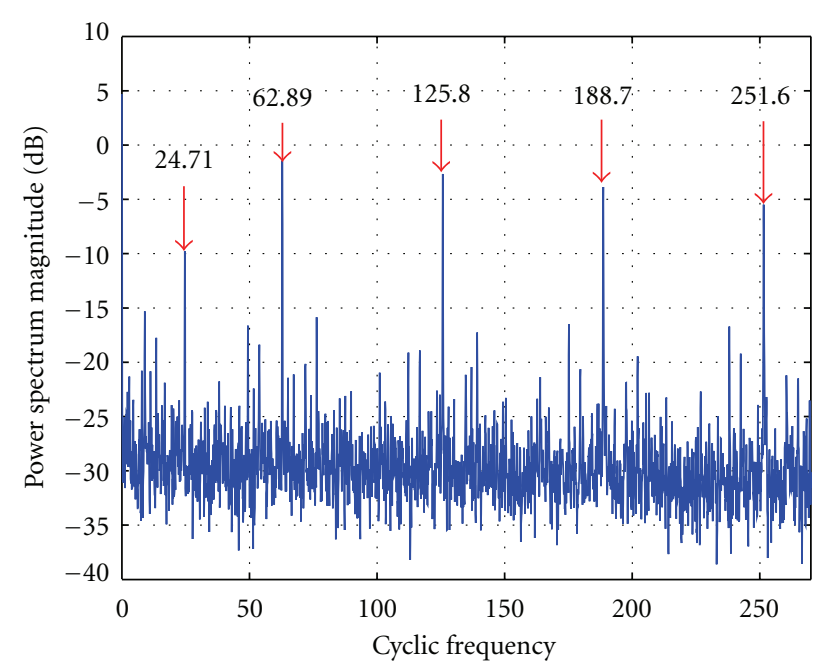

FIGURE 8: Power spectrum density of squared envelope of vibratory signal.

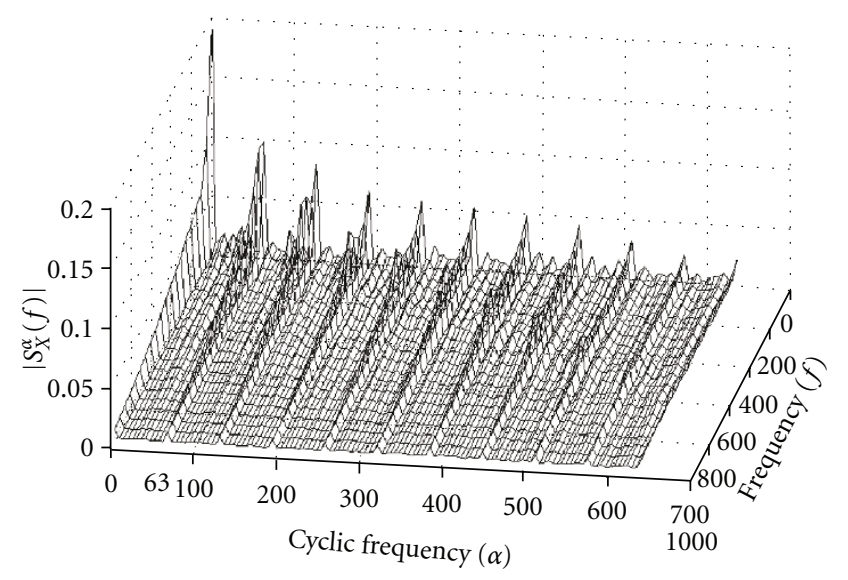

FIGURE 9: Cyclic power spectrum of vibratory signal.

frequency (Figure 10(a)), which will be eliminated by using the cyclostationarity as is shown in Figure 10(b). “*” locates the maximum of the sinusoids.

Surprisingly, it is easier to deal with converter fed; since the electrical frequency is electronically controlled, it is no longer necessary to compensate the electrical fluctuation.

\section{Bearing Fault Signature}

3.1. Effect on Vibration. Bearings, in general, consist of two concentric rings, outer and inner, with balls or rollers between them. Balls are bound by a cage which ensures a uniform distance between them and prevents any contact. Bearing defects can occur as a result of fatigue of the materials under normal operational conditions. First, cracks will appear on the tracks and on the balls. Then, chipping and scuffing-off of material can quickly accelerate the wear of a bearing, and intensive vibrations are generated as a result of the repetitive impacts of the moving components on the defect. Then, it will produce one of the four characteristic 


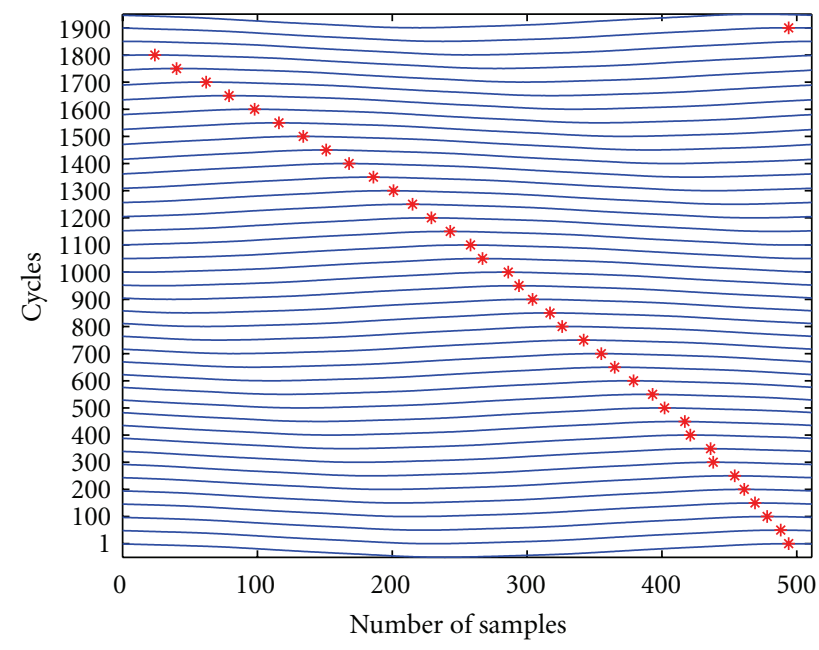

(a) Without synchronization

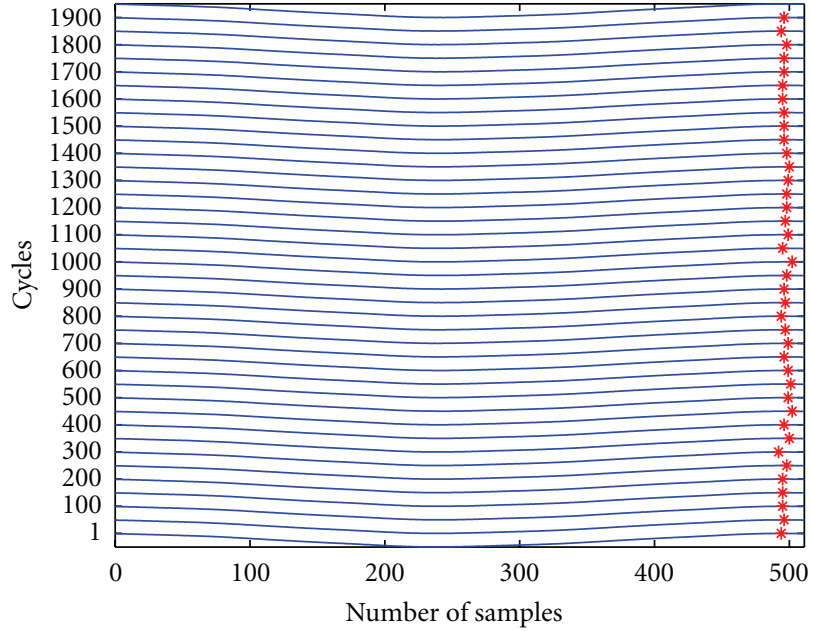

(b) With synchronization

Figure 10: Plot of 1950 cycles of current.

fault frequencies in the machine vibration depending on which bearing surface contains the fault; each bearing defect has its own signature [22], and it is characterized by a frequency (9)-(12) which can be calculated starting from the structure and dimensions of the bearing (Figure 11), where:

$F_{R}:$ rotor frequency,

FTF: cage fault frequency,

BPFI: inner raceway fault frequency,

BPFO: outer raceway fault frequency,

BSF: ball fault frequency,

$B_{d}$ : ball diameter,

$P_{d}$ : pitch diameter,

$N_{B}$ : number of rolling elements, and

$\beta$ : ball contact angle;

$$
\begin{gathered}
\mathrm{FTF}=\frac{1}{2} F_{R}\left(1-\frac{B_{d} \cos \beta}{P_{d}}\right), \\
\mathrm{BPFO}=\frac{N_{B}}{2} F_{R}\left(1-\frac{B_{d} \cos \beta}{P_{d}}\right), \\
\mathrm{BPFI}=\frac{N_{B}}{2} F_{R}\left(1+\frac{B_{d} \cos \beta}{P_{d}}\right), \\
\mathrm{BSF}=\frac{P_{d}}{2 \cdot B_{d}} F_{R}\left[1-\left(\frac{B_{d} \cos \beta}{P_{d}}\right)^{2}\right] .
\end{gathered}
$$

However, these characteristic race frequencies (10) and (11) can be approximated for most bearings with between six and twelve balls by [23]

$$
\begin{aligned}
& \mathrm{BPFO}=0.4 \cdot N_{B} \cdot F_{R}, \\
& \text { BPFI }=0.6 \cdot N_{B} \cdot F_{R} .
\end{aligned}
$$

Single-point defects begin as localised defects on the raceways (or rolling elements). As the rolling elements pass over these defect areas, small collisions occur producing mechanical shock waves. These shock waves then excite the natural frequencies of the machine. This process occurs every time a defect impacts on another part of the bearing, and its rate of occurrence is equal to one of the previously defined characteristic fault frequencies. Restated, inserting familiar terminology, the mechanical resonance frequencies (carriers) are modulated by the characteristic fault frequency (baseband signal) [24].

3.2. From Vibration to Current. The asynchronous motor can be partly modelled according to Figure 12, where:

$$
\begin{aligned}
& i_{1}(t) \text { : stator current of phase } 1, \\
& u_{1}(t) \text { : stator voltage of phase } 1, \\
& R_{s}: \text { stator resistance, } \\
& L_{s}: \text { stator leakage inductance, } \\
& L_{m}: \text { magnetizing inductance, } \\
& R_{r}: \text { rotor resistance, and } \\
& L_{r}: \text { rotor leakage inductance. }
\end{aligned}
$$

This model made of passive component shows that there is a linear relation between the current and the voltage.

There are a number of papers giving evidence of the detection and diagnosis of faults in rolling element bearings, based on the analysis of the current of the induction motor driving the machine $[4,25-28]$. The reason given for the effect of the faults on the current has so far been that the fault in the bearing causes the rotor to become displaced radially in the stator field. It slightly changes the intrinsic parameters of the machine $(L, R, \ldots)$ which are no longer constant. Therefore, the filter between current and voltage changes at the defect period. These cyclic changes of filter 


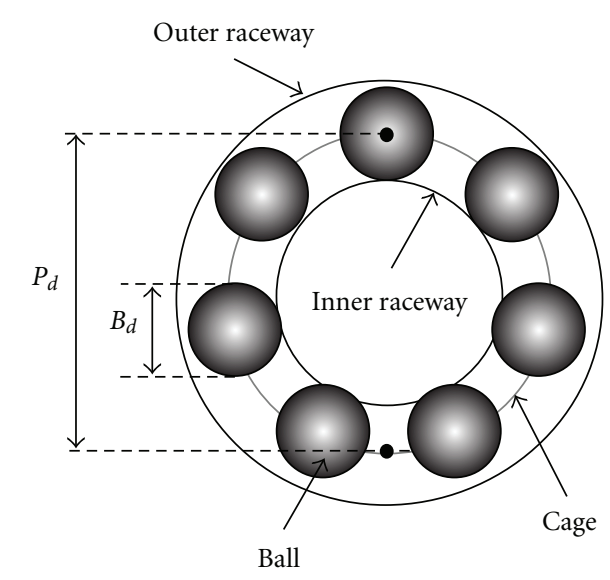

Figure 11: Structure and dimensions of a bearing.

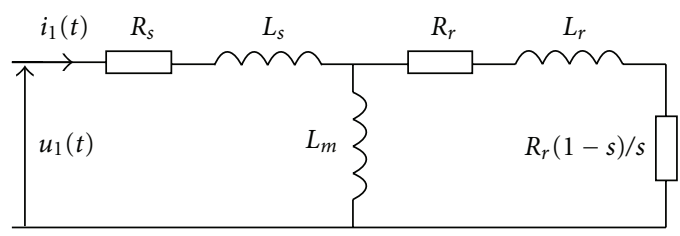

FIGURE 12: Electric model of an asynchronous motor.

parameters create an amplitude modulation of the current [26].

From the above explanation, we retain the fact that the stator current contains an electrical part $s_{e}(t)$ modulated by a mechanical part $m(t)$. It can be written as follows:

$$
i_{1}(t)=s_{e}(t)[1+m(t)]+b(t)
$$

where $b(t)$ is a random noise decorrelated with the other signals.

The "purely" electrical part $s_{e}(t)$ is correlated with the voltage $u_{1}(t)$ and decorrelated with the mechanical part $m(t)$. It should be noted that decorrelation (order 2) is different from independence which concerns all orders;

(i) let $F_{E}$ be the power supply frequency, and

(ii) let $F_{V}$ be one of the characteristic vibration frequencies (FTF, BPFO, BPFI, BSF,...).

The electrical signal contains

(i) a cyclostationary electrical component (in an electrical axis) at frequency $F_{E}$ and its harmonics (where $F_{E}$ is the power supply frequency)

(ii) a cyclostationary mechanical component (in a mixed electrical and mechanical axis due to modulation) at frequency:

$$
F_{B E}=\left|F_{E} \pm k \cdot F_{V}\right| \quad \text { for }(\mathrm{k}=1,2,3, \ldots) .
$$

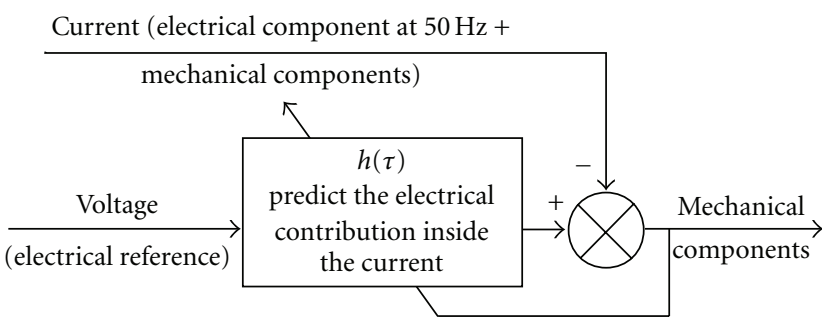

Figure 13: Our Wiener filter approach.

\section{Exploitation of the Electric Signals}

4.1. Problem Statement. The detection of the mechanical defects in electric signals is difficult because of the strong dynamics of the $50 \mathrm{~Hz}$ component, which can mask the presence of other sources carrying information.

A typical current signal is shown on Figure 18. Its spectrum can be seen on Figure 17. Each figure reveals the high dynamics of the $50 \mathrm{~Hz}$ component.

Some methods based on a high-resolution frequency estimation [27, 29] are used to overcome this problem and to assist the fault detection and diagnosis of induction machines. Instead of separate closed peaks, it is proposed here to adapt noise-cancellation techniques on the resynchronised signal in order to reduce the $50 \mathrm{~Hz}$ component (Figure 13).

Here, the noise (our reference) is no longer an unknown signal, but the electrical peak at $F_{E}=50 \mathrm{~Hz}$ which masks the other peaks at $F_{B E}$. The noisy signal is the current that contains a mixture of electrical and mechanical contribution. The denoised signal (i.e., signal without contribution of the reference) is the current without the electrical contribution at $50 \mathrm{~Hz}$.

4.1.1. Estimation of Wiener Filter. In the presence of a fault, the current is impaired by various forms of distortion. Wiener filtering is a method used to recover the original signal as close as possible to the measured signal. Our task is to find the optimal filter $h(t)$ which when applied to the voltage $u_{1}(t)$ produces a signal $\hat{i}(t)$ that is as close as possible to the current $i_{1}(t)$ in terms of least mean squares. In other words, we want to estimate the true signal $i_{1}(t)$,

$$
J=E\left[\left|i_{1}(t)-\hat{i}(t)\right|^{2}\right] .
$$

By minimising $J$, the frequency response of the Wiener filter will be

$$
H(f)=\frac{S_{i_{1} u_{1}}(f)}{S_{u_{1} u_{1}}(f)},
$$

where $S$ is the cross-spectral density.

$$
S_{x, y}(f)=\lim _{T \rightarrow \infty} \frac{1}{T} \mathbb{E}\left\{X_{T}(f) \cdot Y_{T}^{*}(f)\right\},
$$

where $X_{T}(f)$ is the Fourier transform of $x(t)$ windowed in $[-\mathrm{T} / 2, \mathrm{~T} / 2]$. 


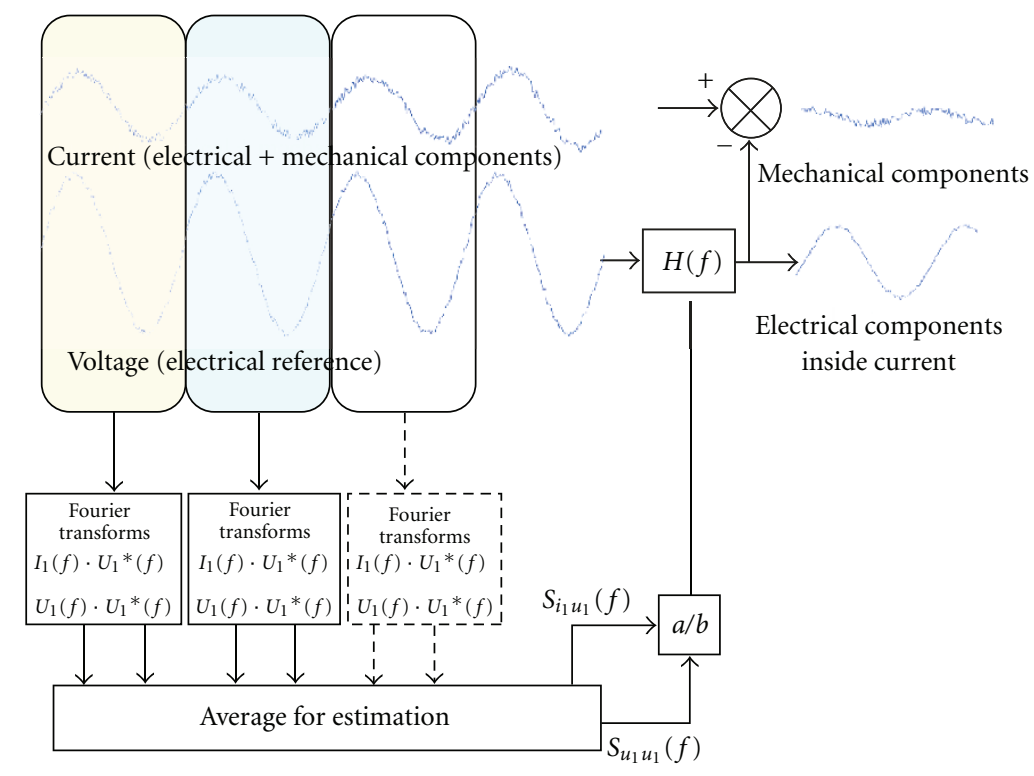

FIGURE 14: Spectrofilter.

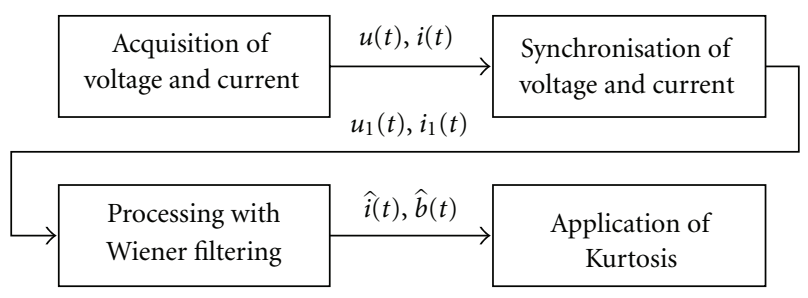

FIGURE 15: Flowchart of the proposed method.

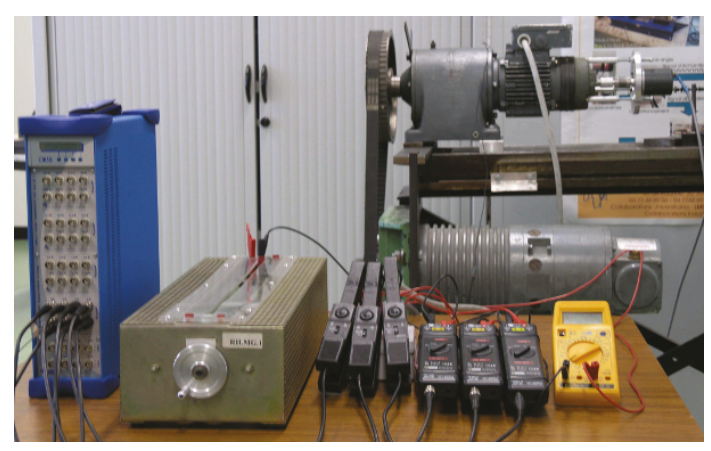

Figure 16: Test rig.

In order to estimate this quantity as shown in Figure 14,

(i) the signal is split into blocks of one cycle,

(ii) a local cross-spectrum is computed, and

(iii) all the local cross-spectra are averaged (the ensemble expectation is substituted with a block expectation).

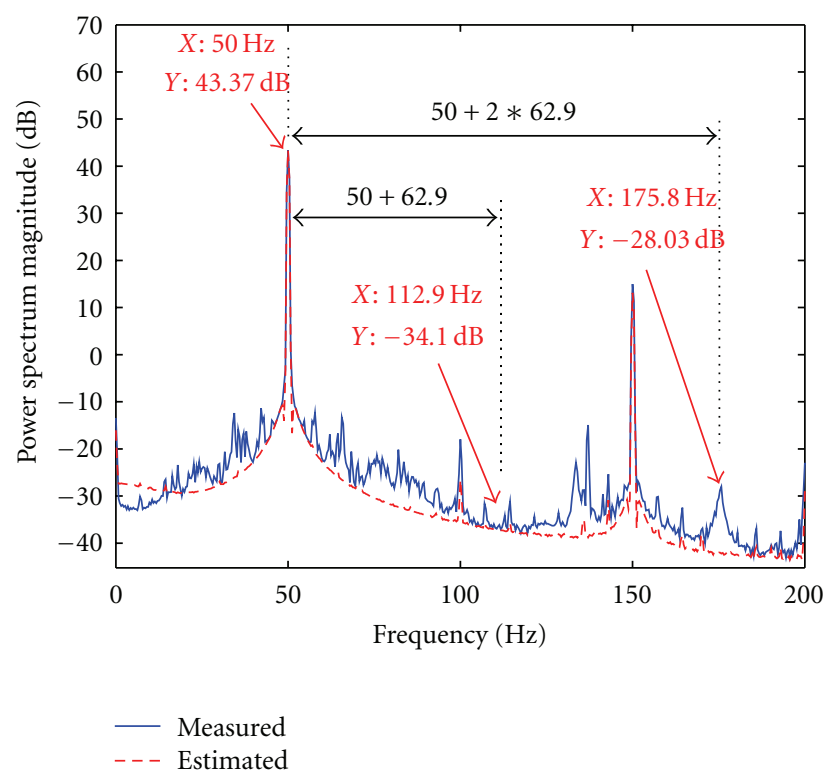

FIGURE 17: Power spectrum density of two currents: (-) measured; (- - -) estimated with synchronization.

The filter $H(f)$ is, therefore, computed by using (17). Next, $\hat{i}(t)$ is retrieved by using

$$
\hat{i}(t)=\mathrm{TF}^{-1}\left[U_{1}(f) H(f)\right],
$$

where $\mathrm{TF}^{-1}$ is the inverse Fourier transform and $U_{1}(f)$ is the Fourier transform of $u_{1}(t)$.

To summarise, Figure 15 is the flowchart of the proposed method where the first step is the acquisition of voltage $u(t)$ and current signals $i(t)$. The test rig is described in Section 5. The next step is to resynchronise the signals 


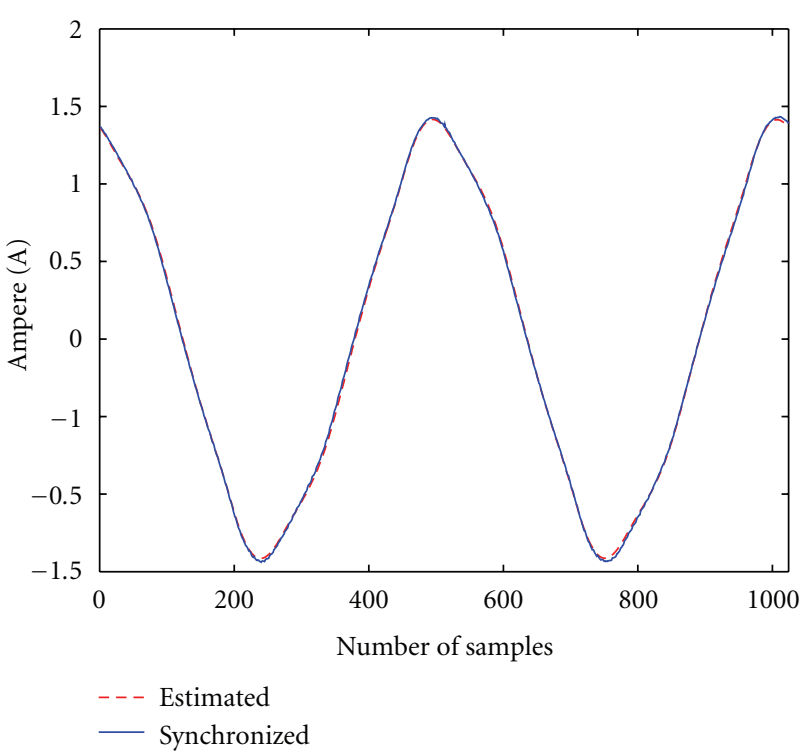

(a) (- - -) estimated current, (-) measured current with synchronisation

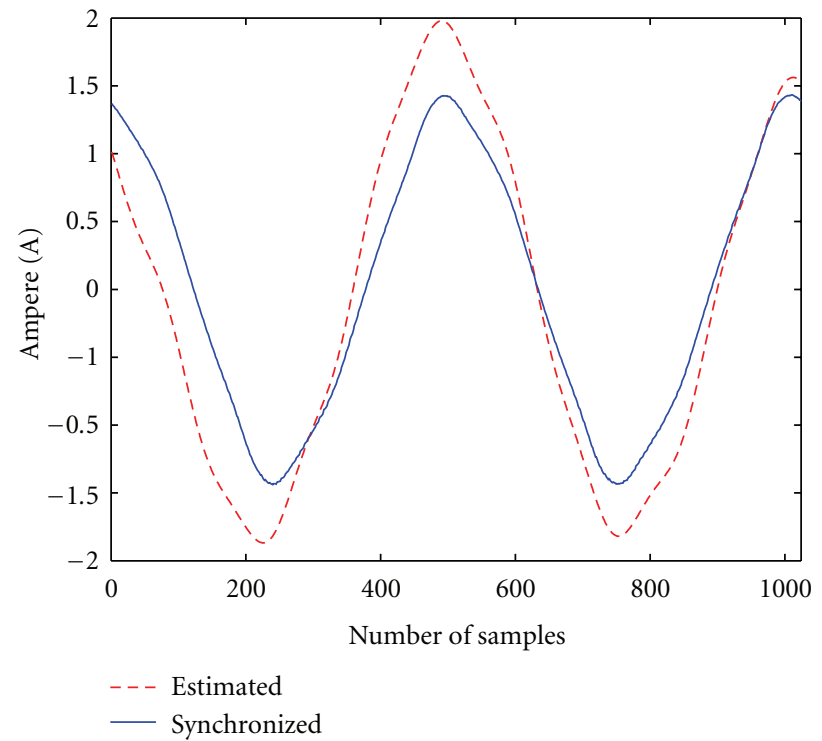

(b) (- - -) estimated current, (-) measured current without synchronisation

FIGURE 18: Superposition of two currents.

to eliminate the power supply fluctuating frequency, the synchronization process being detailed in Section 2.5. The third step is detailed in Section 4, where the Wiener filter is applied to the synchronised signals to estimate the "true" current $\hat{i}(t)$ and, consequently, to estimate the noise $b(t)$ that is related to mechanical information.

4.1.2. Detection of Defect with Kurtosis. Finally, the Kurtosis function is used as an indicator to detect the presence of faults.

The kurtosis could be defined as a measure of peakedness of the probability function. Here, the main advantage of kurtosis is its availability to quantify the impulsive nature of the signal.

Generally, faulty bearings produce an impulsive signal. Therefore, we have chosen the Kurtosis function which is a sensitive indicator used in detecting the presence of periodic impulse signals [30].

The Kurtosis function describes the shape of a random variable's probability density function:

$$
\operatorname{kurt}(X)=\frac{E\left[(X-\mu)^{4}\right]}{\sigma^{4}},
$$

where $\mu$ and $\sigma$ are the mean value and standard deviation of $X$.

A normal random variable has a Kurtosis of 3, and a sine wave has a kurtosis of 1.5 [31].

For vibration analysis, the Kurtosis value should be close to 3 for new bearings. The introduction of a defect onto any contacting surface would generate impulses, thus, changing the distribution of the vibration signal and increasing the Kurtosis value.

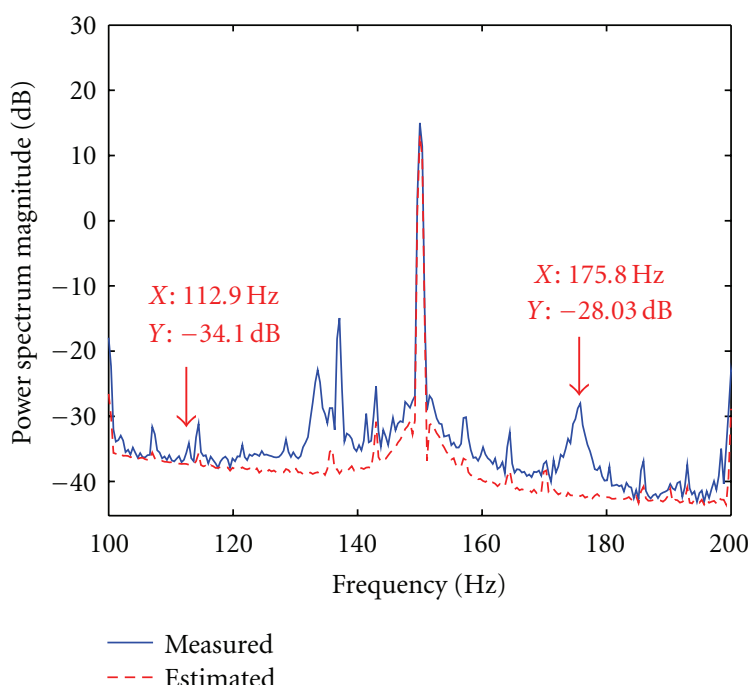

Figure 19: Power spectrum density of two currents: zoom between 100 and $200 \mathrm{~Hz}$.

The advantage of the Kurtosis is to resume the Wiener output signal into a scalar. Therefore, in a predictive maintenance approach, the kurtosis can be monitored against time. If the Kurtosis increased, a sharper (but longer and not automatic) analysis could be made by looking at the signal.

Other classical bearing defect indicators could be used like crest factor, RMS value and so forth.

The results are presented in Sections 5 and 6.

4.2. Other Approach with Wiener Filter. Another approach based on the Wiener filtering for noise cancellation is 


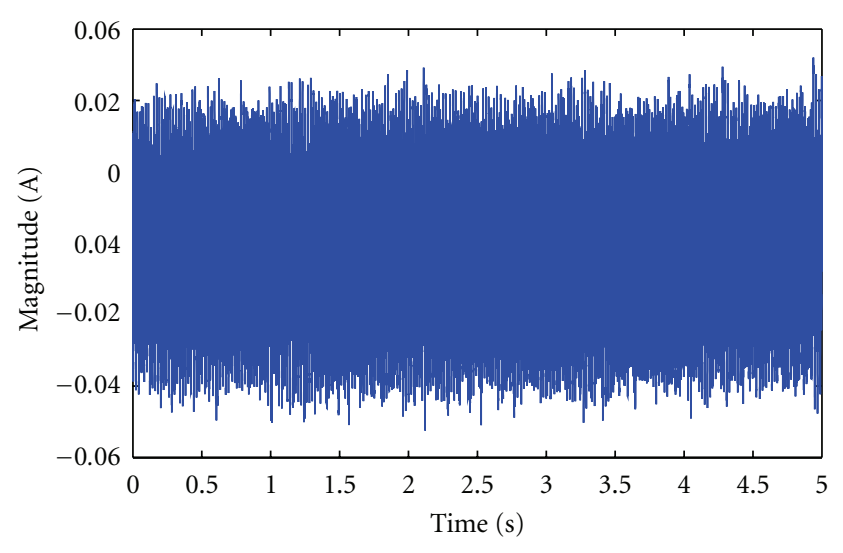

Figure 20: Estimated noise.

proposed in [32], but there are major differences with our work presented in Figure 13. To reduce the $50 \mathrm{~Hz}$, we use a spectrofilter which exploits the supply voltage like an electrical reference of the Wiener filter.

Moreover, the signal is made cyclostationary (by compensating the current fluctuations) before other analyses (spectral, statistical, etc.). It enables a better estimation of the spectrofilter [33,34] and a better rejection of $50 \mathrm{~Hz}$.

The authors in [28] also use a Wiener filter; however, they use the current in a healthy case as reference, and they suppose that the signals are stationary. In addition, our approach can identify exactly the type of defect.

\section{Experimental Test Results}

The test bench (Figure 16) is composed of an asynchronous machine $(1.1 \mathrm{~kW}, 4$ pole motor) and a double-reduction speed reducer coupled to the rotor shaft which is carried by two bearings, where one of them is defective.

This machine is supplied directly by the power supply network of the laboratory and actuates a DC machine which outputs to a rheostat to apply a load. The mechanical vibrations are measured by an accelerometer attached to the machine above the defective bearing; three hook-on ammeters and three differential voltmeters are used for electrical measurements (voltages and currents). The optical encoder fixed at the free end of the shaft gives the angular position of the rotor shaft, it delivers a square signal whose frequency is a multiple of the rotational frequency. This enables the study of the speed fluctuations. For this part of the study, the accelerometer signal and only one phase's current and voltage signals are treated. Table 1 shows the parameters of the bearing taken from the data sheet, and $\cos (\beta)$ is deducted from various measurements. The motor operates at an average shaft speed of $1488 \mathrm{rpm}\left(F_{R}=\right.$ $24.6 \mathrm{~Hz}$ ). A real defect in the outer raceway is located at $62.89 \mathrm{~Hz}$ in the vibration spectrum (Figure 7), and, using the parameters shown in Table 1, the presence of an outer raceway defect at these frequencies is confirmed by (10). The spectrum is very rich because certain frequencies are related to the kinematics of the machine and the gear system.
TABLE 1: Bearing parameters.

\begin{tabular}{lcccccc}
\hline Type & $\begin{array}{c}\text { Outside } \\
\text { diameter }\end{array}$ & $\begin{array}{c}\text { Inside } \\
\text { diameter }\end{array}$ & $N_{B}$ & $P_{d}$ & $B_{d}$ & $\cos (\beta)$ \\
\hline SKF & $47 \mathrm{~mm}$ & $17 \mathrm{~mm}$ & 7 & $32 \mathrm{~mm}$ & 8.735 & 1 \\
$6303-2 \mathrm{Z}$ & & & & & & \\
\hline
\end{tabular}

For this study, we are only interested in what is related to the bearing defect, and studies of other events are envisaged later. Equation (15), predicts the frequencies of interest in the current spectrum to be $\left|F_{E} \pm k * \mathrm{BPFO}\right|$. These current components are indicated on the spectral plots (Figure 17), where $F_{E}=50 \mathrm{~Hz}$ and $\mathrm{BPFO}=62.89 \mathrm{~Hz}$.

It is important to note that the frequency components produced by the bearing defect are relatively small when compared to the rest of the current spectrum. The largest components present in the current spectrum occur at multiples of the supply frequency and are caused by saturation, winding distribution, and the supply voltage. This large difference in magnitude (Figure 17) can make the detection of the current spectrum bearing harmonics a significant problem, which can be solved by using our method.

Figure 18 is a comparison between the "classical" Wiener filter without synchronisation in Figure 18(b) and our approach with synchronization on Figure 18(a). Figure 18(a) highlights the contribution of the cyclostationarity and consequently the synchronization on the estimation of current. The estimated and resynchronised currents are very close, which proves that the estimated filter was the best. It is not the case for Figure 18(b) where the Wiener filter is applied directly to the measured current.

In fact, there were fluctuations relating to mechanical information (vibration and noise) in the measured current hidden by the $50 \mathrm{~Hz}$ frequency and its harmonics. Figure 17 shows a large difference in magnitude between the $50 \mathrm{~Hz}$ and the $112.89 \mathrm{~Hz}$ components equal to $77.47 \mathrm{~dB}$. It should be noticed that, due to synchronization, the estimated current only carries electrical information. Figure 19 is a zooming of Figure 17 between 100 and $200 \mathrm{~Hz}$ showing the good estimation of the current. This enables the subtraction of two currents (measured and estimated) to extract mechanical information as shown in Figure 20. Then, it will be possible to highlight the fluctuations, which have the shape of a vibratory signal and then exploit them better. Figure 21(a) is the power spectral analysis of the estimated noise in a faulty case, it shows that the dynamics of $50 \mathrm{~Hz}$ were eliminated and the difference in magnitude is reduced to $27.6 \mathrm{~dB}$ between $50 \mathrm{~Hz}$ and $112.89 \mathrm{~Hz}$. Moreover, a gain of $1.55 \mathrm{~dB}$ for $112.89 \mathrm{~Hz}$ enables to distinguish it from other very close frequencies. Figure 21(b) is added to help understanding and to compare with the healthy case, where the signature of the outer raceway bearing fault is not present.

A question may be asked: why is there a spectral component at $150 \mathrm{~Hz}$ ? The presence of $150 \mathrm{~Hz}$ is noticed, although the $50 \mathrm{~Hz}$ has disappeared. This is explained by the fact that the fluctuations of $150 \mathrm{~Hz}$ do not exactly follow the fluctuations of $50 \mathrm{~Hz}$, so the synchronised current and the estimated one are not aligned in phase at $150 \mathrm{~Hz}$. We are 


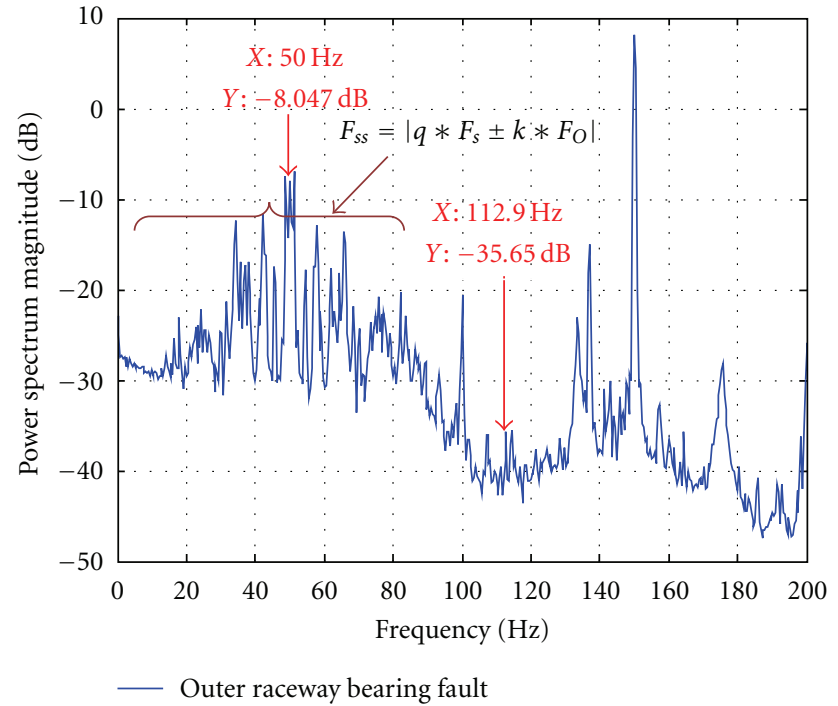

(a) Outer raceway bearing fault

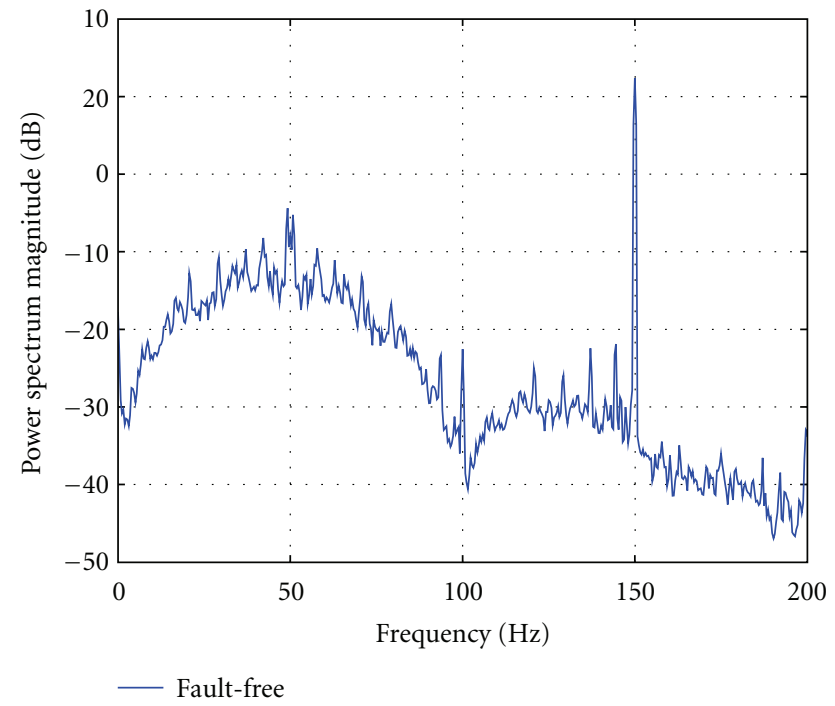

(b) Healthy case

FIgURe 21: Power spectrum density of noise.

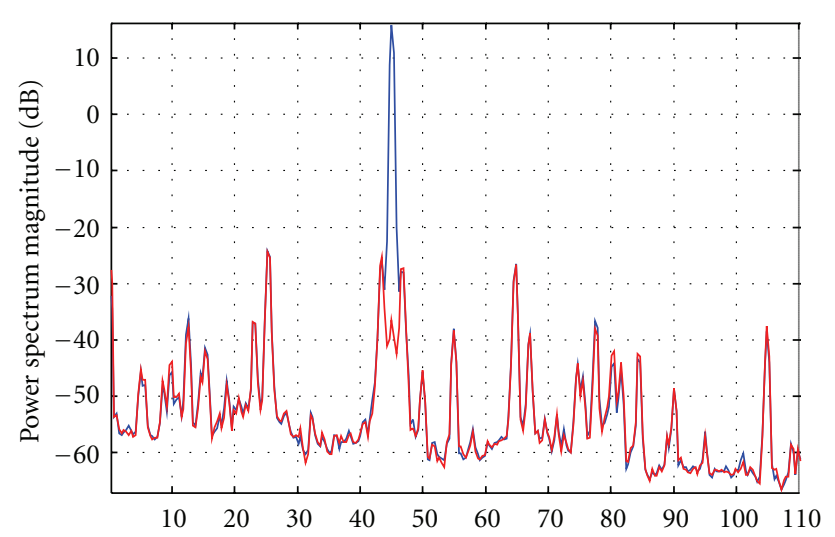

Figure 22: Power spectrum before (blue) and after (red) Wiener filter (fed driven machine).

currently working on the synchronization process so that it can synchronise according to $50 \mathrm{~Hz}$ and its harmonics.

Figure 22 shows the power spectrum before and after Wiener filtering is applied on a fed-driven machine (mains at $45 \mathrm{~Hz}$ ). A reduction of more than $20 \mathrm{~dB}$ can be seen on electrical relative component. It should be noticed that the synchronisation step was not necessary since the electrical frequency generated by the fed converter is very stable.

\section{Application of the Kurtosis Function}

In this application, the Kurtosis function is combined with a Wiener filter to detect bearing faults using electrical signals. It was applied to different signals acquired in different operating conditions; the results are classified in Table 2. For the electrical signal, the Kurtosis value is close to 1.5.
TABLE 2: Kurtosis values.

\begin{tabular}{lcc}
\hline Signal & Healthy & Defect \\
\hline Stator current & 1.46 & 1.57 \\
Accelerometer & 2.83 & 3.51 \\
Residual & 2.16 & 8 \\
Envelope of vibration signal & 12.33 & 66 \\
\hline
\end{tabular}

We cannot detect the bearing fault because of the strong dynamics of $50 \mathrm{~Hz}$ which hide the bearing fault. After cancelation of $50 \mathrm{~Hz}$ harmonics by Wiener filtering, the Kurtosis value increases from 2 to 8 and allows detection of the presence of a fault. We note also that the Kurtosis function is more sensitive on the envelope signal than on the electrical signal.

\section{Conclusion}

This paper discusses the use of signal processing to provide features based on electrical analysis to be used for bearing fault diagnosis. The influence of a bearing damage on the stator current depends on the type of defect and the operating conditions of the machine. Thus, it is difficult to simply detect a bearing fault by observing the stator current, since the mechanical information contained in the electrical current is masked by the strong dynamics of the $50 \mathrm{~Hz}$. The contribution of cyclostationarity to estimate the frequency response of a Wiener filter and the joint resynchronisation of voltage and current make it possible to separate the mechanical part of the electric signal. It means that the $50 \mathrm{~Hz}$ peaks are strongly reduced. Therefore, the mechanical component clearly appears. The use of the Kurtosis function gives an evaluation of the damage and highlights the presence of an anomaly in the machine. 


\section{Appendix}

The analytic part $x_{a}(t)$ of a signal $x(t)$ is produced by passing $x(t)$ in a filter $H(f)$ that sets to zero the negative frequencies and keeps the positive frequencies;

$$
H(f)= \begin{cases}1 & \text { if } f \geq 0 \\ 0 & \text { elsewhere }\end{cases}
$$

For example, the analytic signal of a sine wave

$$
x(t)=k \sin [\varphi(t)]
$$

is an exponential

$$
x_{a}(t)=k e^{j \varphi(t)} .
$$

In the case of a sine wave, it is easy to perform phase demodulation by computing the angle of the analytical signal. Amplitude demodulation is made by extracting the modulus of the analytical signal.

\section{Disclosure}

Parts of this work were presented at the International Conference on Industrial Electronics, IECON2006, Paris, France, in November 2006.

\section{References}

[1] P. O'Donnell, "Report of large motor reliability survey of industrial and commercial installations, part I," IEEE Transactions on Industry Applications, vol. 21, no. 4, pp. 853-864, 1985.

[2] S. Nandi, H. A. Toliyat, and X. Li, "Condition monitoring and fault diagnosis of electrical motors-a review," IEEE Transactions on Energy Conversion, vol. 20, no. 4, pp. 719-729, 2005.

[3] O. V. Thorsen and M. Dalva, "Failure identification and analysis for high-voltage induction motors in the petrochemical industry," IEEE Transactions on Industry Applications, vol. 35, no. 4, pp. 810-818, 1999.

[4] G. B. Kliman and J. Stein, "Induction motor fault detection via passive current monitoring," in Proceedings of International Conference Electric Machine, pp. 13-17, August 1990.

[5] B. Raison, G. Rostaing, and J. P. Rognon, "Signal processing tools for monitoring induction drive," in Proceedings of the 25th Annual Conference of the IEEE Industrial Electronics Society (IECON'99), vol. 3, pp. 1198-1203, December 1999.

[6] J. Ilonen, J. K. Kamarainen, T. Lindh, J. Ahola, H. Kälviäinen, and J. Partanen, "Diagnosis tool for motor condition monitoring," IEEE Transactions on Industry Applications, vol. 41, no. 4, pp. 963-971, 2005.

[7] A. Bellini, G. Franceschini, and C. Tassoni, "Monitoring of induction machines by maximum covariance method for frequency tracking," IEEE Transactions on Industry Applications, vol. 42, no. 1, pp. 69-78, 2006.

[8] J. Grieger, R. Supangat, N. Ertugrul, W. L. Soong, D. A. Gray, and C. Hansen, "Estimation of static eccentricity severity in induction motors for on-line condition monitoring," in Proceedings of the 41st IAS Annual Meeting of IEEE Industry Applications Conference, pp. 2312-2319, Tampa, Fla, USA, October 2006.
[9] M. E. Badaoui, F. Guillet, and J. Danière, "New applications of the real cepstrum to gear signals, including definition of a robust fault indicator," Mechanical Systems and Signal Processing, vol. 18, no. 5, pp. 1031-1046, 2004.

[10] J. R. Stack, T. G. Habetler, and R. G. Harley, "Fault-signature modeling and detection of inner-race bearing faults," IEEE Transactions on Industry Applications, vol. 42, no. 1, pp. 61-68, 2006.

[11] A. R. Mohanty and C. Kar, "Fault detection in a multistage gearbox by demodulation of motor current waveform," IEEE Transactions on Industrial Electronics, vol. 53, no. 4, pp. 12851297, 2006.

[12] M. E. H. Benbouzid, "A review of induction motors signature analysis as a medium for faults detection," IEEE Transactions on Industrial Electronics, vol. 47, no. 5, pp. 984-993, 2000.

[13] A. M. Knight and S. P. Bertani, "Mechanical fault detection in a medium-sized induction motor using stator current monitoring," IEEE Transactions on Energy Conversion, vol. 20, no. 4, pp. 753-760, 2005.

[14] S. Nandi, "Detection of stator faults in induction machines using residual saturation harmonics," IEEE Transactions on Industry Applications, vol. 42, no. 5, pp. 1201-1208, 2006.

[15] A. Ibrahim, M. El Badaoui, F. Guillet, and W. Youssef, "Electrical signals analysis of an asynchronous motor for bearing fault detection," in Proceedings of the 32nd Annual Conference on IEEE Industrial Electronics (IECON '06), pp. 4975-4980, Paris France, November 2006.

[16] J. H. Jung, J. J. Lee, and B. H. Kwon, "Online diagnosis of induction motors using MCSA," IEEE Transactions on Industrial Electronics, vol. 53, no. 6, pp. 1842-1852, 2006.

[17] W. A. Gardner, A. Napolitano, and L. Paura, "Cyclostationarity: half a century of research," Signal Processing, vol. 86, no. 4, pp. 639-697, 2006.

[18] R. B. Randall, J. Antoni, and S. Chobsaard, "The relationship between spectral correlation and envelope analysis in the diagnostics of bearing faults and other cyclostationary machine signals," Mechanical Systems and Signal Processing, vol. 15, no. 5, pp. 945-962, 2001.

[19] J. Antoni and R. B. Randall, "On the use of the cyclic power spectrum in rolling element bearings diagnostics," Journal of Sound and Vibration, vol. 281, no. 1-2, pp. 463-468, 2005.

[20] P. D. McFadden and J. D. Smith, "Vibration monitoring of rolling element bearings by the high-frequency resonance technique-a review," Tribology International, vol. 17, no. 1, pp. 3-10, 1984.

[21] D. Ho and R. B. Randall, "Optimization of bearing diagnostic techniques using simulated and actual bearing fault signals," Mechanical Systems and Signal Processing, vol. 14, no. 5, pp. 763-788, 2000.

[22] R. A. Collacott, Vibration Monitoring and Diagnosis, Wiley, New York, NY, USA, 1979.

[23] R. L. Schiltz, "Forcing frequency identification of rolling element bearings," Sound and Vibration, vol. 24, no. 5, pp. 1619, 1990.

[24] J. R. Stack, R. G. Harley, and T. G. Habetler, "An amplitude modulation detector for fault diagnosis in rolling element bearings," IEEE Transactions on Industrial Electronics, vol. 51, no. 5, pp. 1097-1102, 2004.

[25] A. Ibrahim, M. El Badaoui, F. Guillet, and F. Bonnardot, "A new bearing fault detection method in induction machines based on instantaneous power factor," IEEE Transactions on Industrial Electronics, vol. 55, no. 12, pp. 4252-4259, 2008. 
[26] R. R. Schoen, T. G. Habetler, F. Kamran, and R. G. Bartheld, "Motor bearing damage detection using stator current monitoring," IEEE Transactions on Industry Applications, vol. 31, no. 6, pp. 1274-1279, 1995.

[27] S. H. Kia, H. Henao, and G. A. Capolino, "A high-resolution frequency estimation method for three-phase induction machine fault detection," IEEE Transactions on Industrial Electronics, vol. 54, no. 4, pp. 2305-2314, 2007.

[28] W. Zhou, T. G. Habetler, R. G. Harley, and B. Lu, "Incipient bearing fault detection via stator current noise cancellation using Wiener filter," in Proceedings of the IEEE International Symposium on Diagnostics for Electric Machines, Power Electronics and Drives (SDEMPED '07), pp. 11-16, Cracow Poland, September 2007.

[29] G. Bouleux, A. Ibrahim, F. Guillet, and R. Boyer, "A subspacebased rejection method for detecting bearing fault in asynchronous motor," in Proceedings of International Conference on Condition Monitoring and Diagnosis (CMD '08), pp. 171-174, Beijing China, April 2008.

[30] R. B. W. Heng and M. J. M. Nor, "Statistical analysis of sound and vibration signals for monitoring rolling element bearing condition," Applied Acoustics, vol. 53, no. 1-3, pp. 211-226, 1998.

[31] C. Pachaud, R. Salvetat, and C. Fray, "Crest factor and kurtosis contributions to identify defects inducing periodical impulsive forces," Mechanical Systems and Signal Processing, vol. 11, no. 6, pp. 903-916, 1997.

[32] W. Zhou, T. G. Habetler, and R. G. Harley, "Bearing fault detection via stator current noise cancellation and statistical control," IEEE Transactions on Industrial Electronics, vol. 55, no. 12, pp. 4260-4269, 2008.

[33] J. Max and J. L. Lacoume, Méthodes et Techniques de Traitement du Signal et Applications aux Mesures Physiques, MASSON, Paris, France, 5th edition, 1996.

[34] A. V. Oppenheim and R. W. Schafer, Discrete-Time Signal Processing, Prentice-Hall, Englewood Cliffs, NJ, USA, 1999. 